\title{
Concentrated Oral Dosage Form
}

National Cancer Institute

\section{Source}

National Cancer Institute. Concentrated Oral Dosage Form. NCI Thesaurus. Code C69001.

A concentrate that usually requires dilution prior to oral administration. 